\title{
Index des auteurs et des genres
}

\section{Auteurs évoqués pour leur RDA (ne sont pas pris en compte les exemples cités non commentés explicitement)}

Apollinaire G. 175

Attali J. 221

Artières P. 592

Austen J. 176

Balzac H. de 41, 123-125, 160-161, 171, $267-268,319,445,576,590$

Barthes R. 526, 540, 548, 565, 578

Benjamin W. 569, 574

Boileau N. 589

Bossuet J.-B. 192, 282

Bourbaki N. 485, 569

Butor M. 183, 599

Camilieri A. 592

Camus A. 222-223

Cantilène de Ste Eulalie 343

Céline L.-F. 19, 200, 446, 630

Chateaubriand F.-R. 19

Cohen A. 49, 183, 192-194, 599, 619-620

Colette 46,50

Dard F. (San Antonio) 200

De Gaulle C. 630

Debray R. 556, 603

Diderot D. 128

Döblin A. $183,569,613$

Dumas A. 30

Duras M. 223-224

Eluard P. 589

Ernaux A. 305, 601-602, 613, 618

Flaubert G. 171, 182, 243, 261, 436, 526, 570-571, 574-575, 577, 618-620, 629

Frontier A. 183, 601, 613

Gautier T. 598

Gide A. 26-27, 212, 453, 583

Gombrowicz W. 450

Hasek J. 460

Heredia J.-M. 445

Hugo V. 28, 51, 128, 224, 243, 618
Jabès E. $569,574,577$

Joyce J. 43,522

La Bruyère J. de 578

Laclos C. de 174, 243, 590

La Fontaine J. de 75, 128, 243-244, 453, 614-615

Léautaud P. 424-425, 574

La Fayette (Madame de) 158-159

Mauriac F. 486, 597

Michaux H. 493, 571-572

Millet R. 620-622

Modiano P. 490

Molière 190, 602

Montaigne M. de 577, 590, 629-630

Oulipo 590

Pascal B. 27

Pérec G. 162, 441, 461, 578

Pergaud L. 186

Perrault Ch. 615

Pontalis J.-B. 445, 541, 589

Prévost (Abbé) 19, 591

Proust M. 125, 157, 171, 408, 439, 441, 444, $541-542,576,588,602,629$

Quignard P. 624-625

Retz (Cardinal de) 221, 479

Rousseau J.-J. 404, 410-411, 423, 441, 577, 590,617

Saint-Simon 129

Salvayre L. 589

Sand G. 591

Sarraute N. 448, 569

Sartre J.-P. 46, 455, 526

Sévigné (Madame de) 19, 129

Stendhal 49, 109, 218, 244, 444

Valère V. 606-607

Vaugelas 13-14

Zola E. 134,442 


\section{Types, champs, genres de discours}

Administratif, routinier $457-459$

Champ littéraire

Anthologie 587

Biographie 581, 600, 603

Burlesque, héroï-comique 589

Centon 589-590

Conte 615

Exergue 185, 612

Fable 614

Florilège de citations 180-181, 260, 588,611

Journal (intime, d'écrivain) 424-425, 601

Mémoires 19, 129, 221

Monographie consacrée à un auteur 607-609

Parodie, pastiche 299, 588-589, 602

Poésie 441, 580

Réception à l'Académie

française $609-610$

Recensions, critique littéraire 441

Roman 222-223, 384, 441, 576

Roman épistolaire 19, 174, 243, 590

Théâtre $20,63,583,587$

Échange conversationnel 18-19, 42-43-44, $221,308,348,481,584$

Guide

développement personnel 41,161,479, 616

rédaction, art d'écrire 14, 187

parental 41, 50, 604

touristique 623,628

Juridique, institutionnel 592-593

Presse écrite

Chronique judiciaire 593
Courrier des lecteurs, tribune 453, 603

Échos, potins 594

Éditorial 594

Portrait 593

Revue de presse 8,42

Politique (débat, discours, texte) 191, 422-423, 462, 479, 489, 605-606, 615

Polémique 163, 488,599-600, 606, 617, 621

Production et diffusion de connaissances

Manuel, encyclopédie $60,80,126,230$, 363, 366 ; 458, 479, 592, 595, 612

Dictionnaire de langue $13,15,80,187$,

227, 230, 259-260, 265, 611

Dictionnaire de proverbes, de

citations 42, 180, 260, 587, 604, 612

Écrits scientifiques $162,461,470,480$, 575,$595 ; 604,611$

Sciences humaines $358,465,576,616$ Vulgarisation scientifique $7,480,595$, 611

Publicité 441

Rapport éducatif, psychologique 458, 489

Récit de cure psychanalytique $188,536-539$

Religieux (écrit, sermon) 25, 179-180, 185, 192, 470, 604-605, 612

«Tenant lieu » d'un autre discours

Compte rendu et procès verbal $164-165$,

268, 349, 573

Entretien 19, 220, 357, 529-530,

573-574, 584, 593

Minute de procès 583,611

Rapport de soutenance de thèse 349 ,

583

Résumé 217, 368 